Key messages

- A history of perforated appendix in childhood does not seem to have an adverse effect on female fertility

- The current recommendations of a liberal attitude to exploration in women with suspected appendicitis cannot be justified on the grounds of pervention of infertility

paper. RB planned the statistical analyses and presentation of results, wrote the statistical section of the paper, and edited the manuscript. RA is the guarantor.

Funding: Committee for Research and Development, Jönköping County Council, Health Research Council in Southeast Sweden, Swedish Society for Medical Research, and Lion Foundation, Sweden.

Competing interests: None declared.

1 Andersson RE, Hugander A, Thulin AJ. Diagnostic accuracy and perforation rate in appendicitis: association with age and sex of the patient and with appendicectomy rate. Eur J Surg 1992;158:37-41.

2 Rääf LE. Causes of small intestinal obstruction. Acta Chir Scand 1969;135:67-72

3 Malt RA. The perforated appendix. N Engl J Med 1986;315:1546-7.

4 Hoffmann J, Rasmussen OO. Aids in the diagnosis of acute appendicitis BrJ Surg 1989;76:774-9.

Trimbos-Kemper T, Trimbos B, van Hall E. Etiological factors in tubal infertility. Fertil Steril 1982:37:384-8.
6 Wiig JN, Janssen Jr CW, Fuglesang P, Gjoen OI, Hansen HA, Thue G, et al. Infertility as a complication of perforated appendicitis. Late follow-up of a clinical series. Acta Chir Scand 1979;145:409-10.

7 Thompson WM, Lynn HB. The possible relationship of appendicitis with perforation in childhood to infertility in women. J Pediatr Surg 1971;6:458-61.

8 Kum CK, Ngoi SS, Goh PM, Tekant Y, Isaac JR. Randomized controlled trial comparing laparoscopic and open appendicectomy. Br J Surg 1993;80:1599-600

9 Spirtos NM, Eisenkop SM, Spirtos TW, Poliakin RI, Hibbard LT Laparoscopy-a diagnostic aid in cases of suspected appendicitis. Its use in women of reproductive age. Am J Obstet Gynecol 1987;156:90-4.

10 Jadallah FA, Abdul-Ghani AA, Tibblin S. Diagnostic laparoscopy reduces unnecessary appendicectomy in fertile women. Eur J Surg 1994;160:41-5.

11 Lalos O. Risk factors for tubal infertility among infertile and fertile women. Eur J Obstet Gynecol Reprod Biol 1988;29:129-36.

12 Mueller BA, Daling JR, Moore DE, Weiss NS, Spadoni LR, Stadel BV, et al. Appendectomy and the risk of tubal infertility. $N$ Engl $J$ Med $1986 ; 315: 1506-8$.

13 Puri P, McGuinness EP, Guiney EJ. Fertility following perforated appendicitis in girls. J Pediatr Surg 1989;24:547-9.

14 Geerdsen JP. Sterilitet-senkomplikation til appendicitis acuta perforata hos piger? Nord Med 1988;103:62-3.

15 Bull $\mathrm{P}$. What part is played by acute appendicitis in the causation of sterility in young girls and women? Acta Chir Scand 1932;71:155-65.

16 Källén B. Population characteristics that may confound analysis. In: Källén B. Epidemiology of human reproduction. Florida: CRC Press, 1988: 107-23.

17 Vassilas CA. Parasuicide and appendicectomy. Br J Psychiatry 1988; 152:706-9.

18 Canton G, Santonastaso P, Fraccon IG. Life events, abnormal illness behavior, and appendectomy. Gen Hosp Psychiatry 1984;6:191-5.

19 Joyce PR, Walshe JW, Bushnell JA, Morton JB. Readmissions to hospital after appendicectomy for non-specific abdominal pain. Aust N Z J Surg 1981;51:465-7.

20 Andersson R, Hugander A, Thulin A, Nystrom PO, Olaison G Indications for operation in suspected appendicitis and incidence of perforation. BMJ 1994;308:107-10

(Accepted 29 January 1999)

\title{
Ethnic differences in incidence of stroke: prospective study with stroke register
}

Judith A Stewart, R Dundas, R S Howard, A G Rudd, C D A Wolfe

\section{Abstract}

Objective To identify ethnic differences in the incidence of first ever stroke.

Design A prospective community stroke register (1995-6) with multiple notification sources. Pathological classification of stroke in all cases was based on brain imaging or necropsy data. Rates were standardised to European and world populations and adjusted for age, sex, and social class in multivariate analysis.

Setting A multi-ethnic population of 234533 in south London, of whom $21 \%$ are black.

Results 612 strokes were registered. The crude annual incidence rate was 1.3 strokes per 1000 population per year $(95 \%$ confidence interval 1.20 to $1.41)$ and 1.25 per 1000 population per year (1.15 to 1.35) age adjusted to the standard European population. Incidence rates adjusted for age and sex were significantly higher in black compared with white people $(\mathrm{P}<0.0001)$, with an incidence rate ratio of 2.21 (1.77 to 2.76). In multivariable analysis increasing age $(\mathrm{P}<0.0001)$, male sex $(\mathrm{P}<0.003)$, black ethnic group $(\mathrm{P}<0.0001)$, and lower social class $(\mathrm{P}<0.0001)$ in people aged $35-64$ were independently associated with an increased incidence of stroke. Conclusions Incidence rates of stroke are higher in the black population; this is not explained by confounders such as social class, age, and sex. Ethnic differences in genetic, physiological, and behavioural risk factors for stroke require further elucidation to aid development of effective strategies for stroke prevention in multi-ethnic communities.

\section{Introduction}

Incidence rates of first stroke in different white populations worldwide have been determined..$^{1-3}$ A study in the United States showed a twofold increase in the incidence in one black population, ${ }^{4}$ but no data are available on black populations in Europe. Mortality from stroke, however, is higher among black people than white people in the United Kingdom and the United States. ${ }^{56}$ In Britain, Caribbean immigrants have the highest mortality from stroke, with some evidence that this is due to increased incidence rather than case fatality. ${ }^{78}$ Previous studies in black populations are difficult to interpret because of methodological inconsistencies. $^{79}$

In the United Kingdom there are targets to reduce mortality from stroke. ${ }^{10}$ These are difficult to attain without accurate incidence data. In 1989-90 a community stroke register in south London identified that ethnicity was associated with incidence of stroke in residents aged under 75 years. ${ }^{11}$ The south London stroke register was established to investigate ethnic differences in the natural history of stroke. We present incidence data for the first 2 years (1 January 1995 to 31 December 1996).
Department of Public Health Sciences, Guy's, King's College, and St Thomas's Schoo of Medicine, 5 th Floor, Capital House, London SE1 3QD

Judith A Stewart, lecturer in stroke medicine

R Dundas, research associate C D A Wolfe, reader in public health medicine

Department of Neurology,

St Thomas's

Hospital, London

SE1 5EH

R S Howard, consultant neurologist

Stroke Unit, St Thomas's Hospital, London SE1 5EH

A G Rudd, consultant physician Correspondence to: Dr Wolfe c.wolfe@umds. ac.uk

BMJ 1999;318:967-71 


\section{Methods}

\section{Details of register}

A population based stroke register that recorded first stroke in patients of all age groups was set up with standard criteria. ${ }^{12}$ Data were collected prospectively by the registry team, comprising a neurologist and two nurses. By using 12 referral sources cases of stroke were identified in a defined area corresponding to 22 wards of Lambeth, Southwark, and Lewisham Health Commission. The total population (234 533) is $72 \%$ white, 21\% black (11\% Afro-Caribbean, 7.5\% West African, and 2.5\% black mixed), and 3\% Asian, Bangladeshi, and Pakistani. ${ }^{13}$ Hospital surveillance of admissions for stroke included two teaching hospitals within and three outside the study area. Community surveillance of stroke included patients under the care of all general practitioners within and on the borders of the study area $(n=147)$.

The notification sources were accident and emergency records; hospital wards; brain imaging requests; death certificates; coroner's records; general practitioners; hospital medical staff; community therapists; bereavement officers; hospital based stroke registries; general practice computer records; and "miscellaneous," including notification by patients or relatives of patients. Methods used to ensure complete ascertainment of cases included personal visits to all general practitioners before the project started and 1 year later, and regular communication by telephone, posters, and quarterly newsletters. Use of a weekly stroke clinic or domiciliary visit by the study team were also available to general practitioners.

Death certificates with ICD-9 (international classification of diseases, 9th revision) codes 430 to 434 and 436 were validated according to clinical registration criteria. The Office for National Statistics notified the registry of any patients who had died.

Initial assessments were performed by a doctor (JS or AR). Registration criteria and data collected were checked with the patient's general practitioner and medical records. Patients with transient neurological deficits were included but if the deficit resolved within 24 hours they were not registered. Patients were examined within 48 hours of referral to the register when possible. Difficult cases were discussed (AR, RH) and a consensus reached before registration. Information collected at initial assessment included self definition of ethnic origin (1991 census question ${ }^{11}$ ) and social class (registrar general's codes based on occupation). Ethnic origin was stratified into three groups: black (African-Caribbean, black African, and black other), white, and other (Asian, Pakistani, Indian, Bangladeshi, Chinese, and other). Social class categories were grouped into non-manual (I, II, and III non-manual), manual (III manual, IV, and V) and economically inactive (student, unemployed, unable to work because of disability, being a carer, and retirement).

Classification of pathological type stroke (cerebral infarction, primary intracerebral haemorrhage, and subarachnoid haemorrhage) was based on results from at least one of the following: brain imaging performed within 30 days of onset of stroke (computerised tomography or magnetic resonance imaging), analysis of cerebrospinal fluid (in all living patients with subarachnoid haemorrhage in whom brain imaging was not diagnostic), or necropsy examination. Cases without pathological confirmation of subtype were unclassified.

\section{Analysis}

The denominators for the calculations of incidence rate were the 1996 adjusted estimates of the 1991 census data from the Office for National Statistics for the study area with 10 year age groups $(0-14 ; 15-24$ to $75-84 ;>85)$. Incidence rates specific for sex and ethnic group were adjusted for age to standard European and world populations. To enable comparisons with the MONICA (monitoring trends and determinants in cardiovascular disease) populations, rates adjusted for age were also calculated for ages 35-64 only. Confidence intervals for the age specific rates and age adjusted rates were calculated by using the Poisson distribution. Incidence rate ratios for black to white were calculated by using Poisson regression with adjustment for age and sex. Incidence rate ratios were also calculated to examine ethnic differences in incidence for each pathological type of stroke with adjustment for age and sex. As social class data are ill defined in those aged under 35 or over 64 , a further Poisson regression, adjusted for age, sex, and social class, was performed on cases in patients aged 35-64.

Table 1 Annual incidence rates of first ever stroke, specific for age and sex, per 1000 population in south London stroke register, 1995-6

\begin{tabular}{|c|c|c|c|c|c|c|c|c|c|}
\hline \multirow[b]{2}{*}{ Age group } & \multicolumn{3}{|c|}{ Male } & \multicolumn{3}{|c|}{ Female } & \multicolumn{3}{|c|}{ Overall } \\
\hline & $\begin{array}{c}\text { No of } \\
\text { cases } \\
\text { (2 years) }\end{array}$ & $\begin{array}{c}\text { No in } \\
\text { population } \\
\text { (per year) }\end{array}$ & Rate $(95 \% \mathrm{CI})$ & $\begin{array}{c}\text { No of } \\
\text { cases } \\
\text { (2 years) }\end{array}$ & $\begin{array}{c}\text { No in } \\
\text { population } \\
\text { (per year) }\end{array}$ & Rate $(95 \% \mathrm{CI})$ & $\begin{array}{c}\text { No of } \\
\text { cases } \\
\text { (2 years) }\end{array}$ & $\begin{array}{c}\text { No in } \\
\text { population } \\
\text { (per year) }\end{array}$ & Rate $(95 \% \mathrm{CI})$ \\
\hline$<15$ & 1 & 22853 & 0.02 (0.00 to 0.12$)$ & 0 & 22027 & 0.00 (0.00 to 0.13$)$ & 1 & 44880 & 0.01 (0.00 to 0.06$)$ \\
\hline $15-24$ & 1 & 16196 & $0.03(0.00$ to 0.17$)$ & 2 & 18727 & $0.05(0.00$ to 0.19$)$ & 3 & 34923 & 0.04 (0.01 to 0.13$)$ \\
\hline $25-34$ & 10 & 26671 & 0.19 (0.09 to 0.34$)$ & 5 & 29016 & 0.09 (0.03 to 0.20$)$ & 15 & 55687 & 0.13 (0.08 to 0.22$)$ \\
\hline $35-44$ & 9 & 14178 & $0.32(0.15$ to 0.60$)$ & 7 & 14024 & 0.34 (0.10 to 0.51$)$ & 16 & 28202 & $0.28(0.16$ to 0.46$)$ \\
\hline $45-54$ & 20 & 10140 & 0.98 (0.60 to 1.52$)$ & 16 & 10533 & 0.78 (0.43 to 1.23$)$ & 36 & 20673 & 0.87 (0.61 to 1.21$)$ \\
\hline $55-64$ & 63 & 10226 & 3.08 (2.37 to 3.94$)$ & 28 & 10319 & 1.36 (0.90 to 1.96$)$ & 91 & 20545 & 2.21 (1.78 to 2.72 ) \\
\hline $65-74$ & 95 & 7932 & 5.99 (4.85 to 7.32$)$ & 82 & 9221 & 4.45 (3.54 to 5.52 ) & 177 & 17153 & 5.16 (4.43 to 5.98$)$ \\
\hline $75-84$ & 68 & 3866 & 8.79 (6.83 to 11.15$)$ & 109 & 6068 & 8.98 (7.37 to 10.83$)$ & 177 & 9934 & 8.91 (7.64 to 10.32) \\
\hline$>84$ & 22 & 575 & 19.13 (11.99 to 28.96 ) & 74 & 1961 & 18.87 (14.82 to 23.69 ) & 96 & 2536 & 18.92 (15.33 to 23.11$)$ \\
\hline Total/crude & 289 & 112637 & 1.28 (1.14 to 1.44$)$ & 323 & 121896 & 1.33 (1.18 to 1.48$)$ & 612 & 234533 & 1.31 (1.20 to 1.41$)$ \\
\hline \multicolumn{10}{|c|}{ Standardised to: } \\
\hline World & & & $0.96(0.84$ to 1.07$)$ & & & $0.70(0.61$ to 0.78$)$ & & & $0.82(0.75$ to 0.89$)$ \\
\hline European & & & $1.43(1.26$ to 1.60$)$ & & & $1.08(0.96$ to 1.20$)$ & & & 1.25 (1.15 to 1.35$)$ \\
\hline
\end{tabular}


Table 2 Annual incidence rates, specific for age and ethnic origin, for first in a lifetime stroke per 1000 population in south London stroke register, 1995-6

\begin{tabular}{|c|c|c|c|c|c|c|c|c|c|}
\hline \multirow[b]{2}{*}{ Age group } & \multicolumn{3}{|c|}{ White } & \multicolumn{3}{|c|}{ Black } & \multicolumn{3}{|c|}{ Other } \\
\hline & $\begin{array}{c}\text { No of } \\
\text { cases } \\
\text { (2 years) }\end{array}$ & $\begin{array}{c}\text { No in } \\
\text { population } \\
\text { (per year) }\end{array}$ & Rate $(95 \% \mathrm{CI})$ & $\begin{array}{c}\text { No of } \\
\text { cases } \\
\text { (2 years) }\end{array}$ & $\begin{array}{c}\text { No in } \\
\text { population } \\
\text { (per year) }\end{array}$ & Rate $(95 \%$ CI) & $\begin{array}{c}\text { No of } \\
\text { cases } \\
\text { (2 years) }\end{array}$ & $\begin{array}{c}\text { No in } \\
\text { population } \\
\text { (per year) }\end{array}$ & Rate $(95 \%$ CI) \\
\hline$<15$ & 1 & 24757 & $0.02(0.00$ to 0.11$)$ & 0 & 14719 & $0(0.00$ to 0.13$)$ & 0 & 5404 & $0(0.00$ to 0.34$)$ \\
\hline $15-24$ & 1 & 23575 & $0.02(0.00$ to 0.12$)$ & 2 & 8102 & $0.12(0.02$ to 0.45$)$ & 0 & 3246 & $0(0.00$ to 0.57$)$ \\
\hline $25-34$ & 4 & 39883 & $0.05(0.01$ to 0.13$)$ & 11 & 12397 & $0.44(0.22$ to 0.79$)$ & 0 & 3407 & $0(0.00$ to 0.54$)$ \\
\hline $35-44$ & 12 & 21238 & $0.28(0.15$ to 0.49$)$ & 4 & 4818 & 0.42 (0.11 to 1.06) & 0 & 2146 & 0 (0.00 to 0.86$)$ \\
\hline $45-54$ & 25 & 15381 & 0.81 (0.53 to 1.20$)$ & 6 & 3849 & $0.78(0.29$ to 1.70$)$ & 5 & 1443 & $1.73(0.56$ to 4.04$)$ \\
\hline $55-64$ & 58 & 15944 & 1.82 (1.38 to 2.35 ) & 28 & 3622 & 3.87 (2.57 to 5.59) & 5 & 979 & 2.55 (0.83 to 5.96$)$ \\
\hline $65-74$ & 139 & 15192 & 4.57 (3.85 to 5.40$)$ & 34 & 1595 & 10.66 (7.38 to 14.89$)$ & 4 & 366 & 5.46 (1.49 to 13.99$)$ \\
\hline $75-84$ & 161 & 9410 & 8.55 (7.28 to 9.98) & 12 & 358 & 16.76 (8.66 to 29.27$)$ & 4 & 166 & 12.05 (3.28 to 30.84$)$ \\
\hline$>84$ & 88 & 2454 & 17.93 (14.38 to 22.09) & 5 & 39 & 64.10 (20.81 to 149.58$)$ & 3 & 43 & 34.88 (7.19 to 101.92 \\
\hline Total/crude & 489 & 167834 & 1.46 (1.33 to 1.59$)$ & 102 & 49499 & 1.03 (0.85 to 1.26$)$ & 21 & 17200 & $0.61(0.38$ to 0.93$)$ \\
\hline \multicolumn{10}{|c|}{ Standardised to: } \\
\hline World & & & $0.73(0.66$ to 0.81$)$ & & & $1.63(1.25$ to 2.02$)$ & & & $1.02(0.58$ to 1.47$)$ \\
\hline European & & & 1.12 (1.02 to 1.23$)$ & & & 2.56 (1.87 to 3.25 ) & & & 1.62 (0.90 to 2.34) \\
\hline
\end{tabular}

Case fatality rates were calculated at 7, 28, 90, and 180 days after stroke. Logistic regression with adjustment for age and sex was used to compare ethnic groups.

\section{Results}

The south London stroke register registered 612 patients with first stroke. Patients were identified by between one and five notification sources, with a median of three. The most common referral sources were hospital wards, death certificates, and hospital medical staff. One hundred patients $(16.3 \%)$ were not admitted to hospital. Nine of these were identified after death.

Of the 612 patients registered, 289 were men; 489 were white, 102 were black, and 21 were classified "other." The mean (range; SD) age of all first strokes was 71.3 (12 to $99 ; 14.4$ ) years; 73.6 (12 to $99 ; 13.2)$ years for white people, 61.4 (17 to $94 ; 16.2)$ years for black people, and 66.9 (49 to $87 ; 12.6)$ years for "other" $(\mathrm{P}<0.0001)$. There were 136 non-manual, 368 manual, and 108 inactive patients.

Pathological diagnosis of stroke subtype was confirmed in 536 cases. The distribution of each subtype was cerebral infarction in 419; primary intracerebral haemorrhage in 79; and subarachnoid haemorrhage in 43; 71 were unclassified. Of the unclassified cases, $19(27 \%)$ were community patients and 20 patients (one community, 19 hospital) died within 48 hours of onset of stroke.

The crude total incidence rate per 1000 population was 1.31 (95\% confidence interval 1.20 to 1.41$) ; 1.25$ (1.15 to 1.35 ) standardised to the European and 0.82 ( 0.75 to 0.89 ) standardised to the world populations. Incidence rates (age adjusted to the standard European population) were higher in men than in women (table $1)$. The incidence rate ratio for men compared with women showed a higher rate in men $(1.3 ; 1.1$ to 1.5 ; $\mathrm{P}<0.003)$. Across all age groups incidence rates were higher in black compared with white populations except in those aged 45-54 years (table 2). The incidence rate ratio adjusted for age and sex in black compared with white patients was 2.21 (1.77 to 2.76; $\mathrm{P}<0.0001)$. The incidence rates increased with age in all ethnic groups, and age was a significant independent factor $(\mathrm{P}<0.0001)$ (tables 1 and 2$)$.

Social class for those aged between 35 and 64 was a significant independent factor. The incidence rate ratio between patients in manual (99 cases) and non-manual classes (31 cases) was 2.11 (1.37 to $3.25 ; \mathrm{P}<0.0001$ ). Thirteen patients $(9 \%)$ were classified as economically inactive. Within the 35-64 age group the incidence rate ratios between black and white groups before and after adjustment for social class were 1.71 (1.17 to 2.49 ; $\mathrm{P}=0.005)$ and 1.53 (1.04 to $2.23 ; \mathrm{P}=0.029)$, respectively. In this age range ethnicity was significantly associated with incidence of stroke after adjustment for age, sex, and social class. Irrespective of ethnicity, age specific incidence rates for all subtypes of stroke increased with age. The incidence rates adjusted for age and sex for each subtype of stroke were higher in black people than white people (table 3). The incidence rate ratios for black:white people were 1.99 (1.50 to 2.63; $\mathrm{P}<0.001)$ for cerebral infarction; 3.28 (1.83 to $5.77, \mathrm{P}<0.001)$ for primary intracerebral haemorrhage; and 2.36 (1.2 to $4.63, \mathrm{P}=0.013)$ for subarachnoid haemorrhage. The age and sex adjusted case fatality rates at 7, 28, 90 and 180 days showed no significant difference between ethnic groups (table 4).

Table 3 Annual incidence rates ( $95 \%$ confidence interval) for stroke by subtype and ethnic group adjusted for age to standard European population per 1000 (1995-6)

\begin{tabular}{|c|c|c|c|c|c|c|}
\hline \multirow[b]{2}{*}{ Type of stroke } & \multicolumn{2}{|r|}{ White } & \multicolumn{2}{|r|}{ Black } & \multicolumn{2}{|r|}{ Overall } \\
\hline & $\begin{array}{c}\text { No of } \\
\text { patients }\end{array}$ & $\begin{array}{l}\text { Annual incidence rate } \\
(95 \% \mathrm{Cl})\end{array}$ & $\begin{array}{c}\text { No of } \\
\text { patients }\end{array}$ & $\begin{array}{c}\text { Annual incidence rate } \\
(95 \% \mathrm{CI})\end{array}$ & $\begin{array}{c}\text { No of } \\
\text { patients }\end{array}$ & $\begin{array}{c}\text { Annual incidence rate } \\
(95 \% \text { CI) }\end{array}$ \\
\hline Cerebral infarction & 344 & 0.79 (0.70 to 0.88$)$ & 64 & 1.86 (1.23 to 2.50$)$ & 423 & 0.87 (0.76 to 0.96$)$ \\
\hline $\begin{array}{l}\text { Primary intracerebral } \\
\text { haemorrhage }\end{array}$ & 54 & $0.12(0.09$ to 0.16$)$ & 18 & $0.38(0.19$ to 0.57$)$ & 78 & $0.16(0.13$ to 0.20$)$ \\
\hline Subarachnoid haemorrhage & 30 & 0.09 (0.05 to 0.12$)$ & 13 & $0.12(0.04$ to 0.20$)$ & 43 & 0.09 (0.06 to 0.12$)$ \\
\hline Unclassified & 61 & 0.12 (0.09 to 0.16$)$ & 7 & $0.20(0.04$ to 0.36$)$ & 68 & $0.13(0.10$ to 0.16$)$ \\
\hline
\end{tabular}


Table 4 Case fatality. Number of deaths (percentage) by ethnic group

\begin{tabular}{lccccc} 
Time since stroke (days) & Overall $(\mathbf{n}=\mathbf{6 1 2})$ & White $(\mathbf{n}=\mathbf{4 8 9})$ & Black $(\mathbf{n}=\mathbf{1 0 2})$ & Other $(\mathbf{n}=\mathbf{2 1})$ & P value $($ adjusted) \\
\hline 7 & $101(16.5)$ & $86(17.6)$ & $13(12.8)$ & $2(9)$ & 0.605 \\
\hline 28 & $159(26.0)$ & $134(27.4)$ & $22(21.6)$ & $3(14)$ & 0.592 \\
\hline 90 & $200(32.7)$ & $168(34.4)$ & $27(26.5)$ & $5(24)$ & 0.894 \\
\hline 180 & $221(36.1)$ & $186(38.0)$ & $30(29.4)$ & $5(24)$ & 0.766
\end{tabular}

\section{Discussion}

\section{Case ascertainment}

The validity of any incidence study depends on complete and accurate ascertainment of cases. Core criteria for stroke incidence studies ${ }^{12}$ were incorporated by using standard definitions, a prospective study design, an adequate and defined population, and notification by multiple overlapping sources.

The most difficult cases to identify are non-fatal strokes in the community and non-fatal strokes in patients admitted to hospital while they are away from the study area. Both groups of patients could be identified by general practitioners' notification, regular prompting of general practitioners by the research team, checks on general practice diagnostic computer records, and regular checks of requests for brain imaging from outpatient departments when the referral history suggested a diagnosis of stroke. The methods used for patient notification helped to ensure as near complete case ascertainment as possible.

\section{Population denominator data}

The 1991 census data on the population denominator may not be accurate; no data were obtained for $2.2 \%$ of the population and underenumeration was highest in men aged 20-29 years. ${ }^{14}$ As incidence rates for stroke in all ethnic groups are low in this age group denominator underenumeration would probably not influence the ethnic differences found. Population growth, mobility, and cross boundary effects are difficult to estimate and may differ between ethnic groups. These factors, for which we have not been able to control, may influence observed incidence rates.

\section{Stroke incidence}

The total stroke incidence rate of 1.25 per 1000 population, age adjusted to the standard European population, was lower than that reported over 10 years ago in the Oxfordshire community stroke project (1981-6) (1.6 per 1000 white population). ${ }^{3}$ The estimates from the south London register are within the range of rates reported in registers in Europe and New Zealand. ${ }^{15-17}$

This first European register that included black people has shown significant ethnic differences in stroke incidence. The adjusted incidence rate ratio of black:white people was 2.2 with an age adjusted incidence rate of 2.6 per 1000 black people. This compares with some of the highest reported rates worldwide (2.8 per 1000 in Japan and 2.9 per 1000 men in Finland). ${ }^{1}$ In one study among black people in the United States the incidence of first stroke that required admission to hospital or that was fatal and resulted in necropsy reported was 2.9 per $1000,1.6$ times greater than the rate reported in white people. ${ }^{18}$ The excess incidence of stroke among black people in the south London registry is similar to the 2.4-fold increase reported in the Northern Manhattan stroke study (2.2 in black people and 0.9 in white people per 1000). ${ }^{4}$

\section{Pathological stroke type}

We have shown increased incidence rates for all pathological subtypes of stroke in black people, with primary intracerebral haemorrhage having the highest black: white incidence rate ratio. Higher rates of haemorrhagic stroke in black people but of embolic strokes and extracranial occlusive vascular disease in white people have been reported in a number of hospital stroke series. ${ }^{19}$ In some hospital series ease of access to healthcare facilities and use of diagnostic tests differ between black and white patients, thereby introducing selection bias. ${ }^{6}{ }^{19}$ In the register there was no significant difference in incidence rates of unclassified stroke between ethnic groups.

\section{Social class}

Ethnic differences in social class have been suggested as contributory to the excess mortality from stroke in black people compared with white people in the United States. ${ }^{20}$ Adjustment for social class has not been performed in any published study on stroke incidence including black subjects. In the register adjustment of incidence rates for social class was possible only within the limited age range (35-64) for which census data on social class were available. There are problems with registrar general's coding of social class, particularly in the exclusion of housewives, carers, students, and the unemployed, but it was the only measure available. Although the reduced sample size of cases of stroke in those aged 35-64 meant that the confidence intervals of black:white incidence rate ratios after adjustment for social class were wide, ethnicity was still significantly associated with stroke incidence.

Increased incidence of stroke in lower socioeconomic groups in both black and white people in the register is consistent with social class variation in stroke mortality and incidence reported in other studies. ${ }^{21} 22$

\section{Risk factors}

The excess incidence of stroke among black people compared with white people was not explained by social class, age, or sex. Differences in genetic, physiological, and behavioural risk factors that may account for ethnic differences in stroke incidence require further elucidation. A higher prevalence of hypertension and diabetes among black people compared with white people has been reported, ${ }^{23}$ and a recent study suggests ethnic differences in genetic predisposition to hypertension. ${ }^{24}$ Ethnic differences in these risk factors alone, however, do not account for the increased risk of stroke among black people. ${ }^{5} 7$ 
Key messages

- Incidence rates of first ever stroke adjusted for age and sex are twice as high in black people compared with white people

- This excess incidence cannot be accounted for by differences in social class in ages 35-64

- Black people tend to have their first stroke at a younger age than white people

- The excess incidence is found in all pathological types of stroke but is greatest for primary intracerebral haemorrhage

- There is no difference between ethnic groups in case fatality up to 6 months after stroke

\section{Case fatality}

Case fatality at 28 days was $26 \%$, which is comparable with rates reported of $18 \%$ and $33 \%$ in two Italian centres. ${ }^{1}$ The 28 day case fatality rates for patients aged 35-64 years reported in MONICA were $15 \%$ to $49 \%$ in men and $18 \%$ to $57 \%$ in women; our rate of $17 \%$ (for the same age group) is towards the lower end of the ranges and comparable with rates reported in Nordic populations. ${ }^{1}$ Some studies have suggested ethnic differences in survival from stroke. ${ }^{4}$ In the register there were no significant differences in case fatality between black and white people up to 6 months after stroke.

\section{Conclusion}

We have shown important ethnic differences in the incidence of stroke. Investigation of ethnic differences in risk factors for stroke is needed to account for the excess incidence among black people to plan effective prevention and management of stroke in multi-ethnic communities.

We thank fieldworkers Elizabeth Richardson, Tania Collela, and Francis Bunn for their help with data collection and all general practitioners and general practice and hospital staff in the area who have supported the study.

Funding: Northern and Yorkshire Region Research and Development Programme. Glaxo Wellcome plc contributed a research and development grant.

Contributors: JS initiated and coordinated the formulation of the primary hypothesis, discussed core ideas, designed the protocol, particularly the documentation of clinical data, and participated in data collection, analysis, and writing of the paper. RD participated in the documentation, analysis, and interpretation of the data, quality control, and writing of the paper. $\mathrm{RH}$ initiated research, discussed core ideas, participated in protocol design, data documentation, and analysis, and contributed to the paper. AR initiated research, discussed core ideas, participated in protocol design, collection, documentation, and analysis of data, and contributed to the paper. CW, the principal instigator of the south London stroke register research project, initiated research, participated in the design and execution of the study, discussed core ideas, participated in the documentation, analysis, and interpretation of the data, and edited the paper. $\mathrm{CW}$ is the guarantor.

1 Thorvaldsen P, Asplund K, Kuulasmaa K, Rajakangas A, Schroll M. Stroke incidence, case fatality and mortality in the WHO MONICA project. Stroke 1995;26:361-7.

2 Broderick JP, Phillips SJ, Whisnant JP, O'Fallon WM, Bergstrahl EJ Incidence rates of stroke in the eighties: the end of the decline in stroke? Stroke 1989:20:577-82.
3 Bamford J, Sandercock P, Dennis M. A prospective study of acute cerebrovascular disease in the community: the Oxfordshire community stroke project 1981-86. 1. Methodology, demography and incident cases of first ever stroke. J Neurol Neurosurg Psychiatry 1988;51:1373-80.

4 Sacco RL, Boden-Albala B, Gan R, Chen X, Kargman DE, Shea S. Stroke incidence among white, black, and Hispanic residents of an urban Community. The Northern Manhattan stroke study. Am I Epidemiol 1998;147:259-68.

5 Balarajan R. Ethnic differences in mortality from ischaemic heart disease and cerebrovascular disease in England and Wales. BMJ 1991;302:560-4

6 Otten M, Teutsch S, Williamson D, Marks J. The effect of known risk fac tors on the excess mortality of black adults in the United States. JAMA 1990;263:845-50.

7 Sacco R, Hauser W, Mohr J. Hospitalized stroke in blacks and Hispanics in northern Manhattan. Stroke 1991:22:1491-6.

8 Kittner S, White L, Losonczy K, Wolf P, Hebel R. Black-white differences in stroke incidence in a national sample: the contribution of hypertension and diabetes mellitus. JAMA 1990;264:1267-70.

9 Parrish H, Payne G, Allen W, Goldner J, Sauer H. Mid-Missouri stroke survey: a preliminary report. Missouri Med 1966;63:816-8.

10 Secretary of State for Health. The health of the nation: a strategy for health in England. London: HMSO, 1992

11 Wolfe C, Taub N, Woodrow J, Richardson E, Warburton F, Burney P. Does the incidence, severity, or case fatality of stroke vary in southern England? J Epidemiol Community Health 1993;47:139-43.

12 Malmgren R, Bamford J, Warlow C, Sandercock P. Geographical and secular trends in stroke incidence. Lancet 1987;ii:1196-200.

13 Director of Public Health. Annual report 1995-1996. London: Lambeth Southwark and Lewisham Health Commission, 1996.

14 Majeed F, Cook D, Poloniecki J, Martin D. Using data from the 1991 census. $B M J$ 1995;310:1511-4

15 Bonita R, Beaglehole R, North JDK. Event, incidence and case-fatality rates of cerebrovascular disease in Auckland, New Zealand. Am J Epidemiol 1984;120:236-43.

16 Eisenblatter D, Heinemann L, Classen E. Community-based stroke incidence trends from the 1970s through the 1980s in East Germany. Stroke 1995;26:919-23.

17 Korv J, Roose M, Kaasik AE. Stroke registry of Tartu, Estonia. Cerebrovas Dis 1997;7:154-62.

18 Broderick J, Brott T, Kothari R, Miller R, Khowry J, Pancioli A. The Greater Cincinnati/Northern Kentucky stroke study. Preliminary first-ever and total incidence rates of stroke among blacks. Stroke 1998;29:415-21.

19 Gross C, Kase C, Mohr J, Cunningham S, Baker W. Stroke in South Alabama: incidence and diagnostic features in a population-based study Stroke 1984:15:249-54.

20 Howard G, Russell GB, Anderson R, Evans GW, Morgan T, Howard VJ Role of social class in excess black stroke mortality. Stroke 1995;26: 1759-63.

21 Casper M, Wing S, Strogatz D. Variation in the magnitude of black-white differences in stroke mortality by community occupational structure. J Epidemiol Community Health 1991;45:302-6.

22 Shaper AG, Phillips AN, Pocock SJ, Walker M, Macfarlane PW. Risk factors for stroke in middle aged British men. BMJ 1991;302:1111-6.

23 Cruickshank FB, Beevers D, Osbourne V, Haynes R, Corlett J, Selby S Heart attack, stroke, diabetes and hypertension in West Indians, Asians and whites in Birmingham, England. BMJ 1980;281:1108

24 Baker EH, Dong YB, Sagnella GA, Rothwell M, Onipinla AK, Markandu ND. Association of hypertension with T594M mutation in beta subunit of epithelial sodium-channels in black people resident in London. Lancet 1998;351:1388-92.

(Accepted 10 February 1999)

\section{Endpiece \\ Time}

The increase of disorder or entropy with time is one example of what is called an arrow of time, something that distinguishes the past from the future, giving a direction of time. There are at least three different arrows of time. First, there is the thermodynamic arrow of time, the direction of time in which disorder or entropy increases. Then, there is the psychological arrow of time. This is the direction in which we feel time passes, the direction in which we remember the past but not the future. Finally, there is the cosmological arrow of time. This is the direction of time in which the universe is expanding rather than contracting.

Stephen Hawking, A Brief History of Time, Bantam Books, 1988 